\title{
Leprosy control in The Gambia
}

\author{
HJR MEESTERS \\ Leprosy Control Programme, PO Box 1, Makeni, Sierra Leone.
}

Received for publication 2 January 1980

Summary The changes in the epidemiological situation of leprosy in the Republic of The Gambia are assessed from the statistics of the registered patients and through comparison of several leprosy surveys.

A marked decline in the number of registered cases (from 7,000 in 1970 to 1,675 in 1977$)$ and in the estimated prevalence of leprosy $(2.5 \%$ in $1947,0.6 \%$ in 1977) is demonstrated.

Several aspects of leprosy control in The Gambia are discussed. The need to continue a specialized programme is stressed.

\section{Introduction}

The Republic of the Gambia is situated in West Africa extending along both banks of the River Gambia to a distance of 11 to $24 \mathrm{~km}$. and for about $482 \mathrm{hm}$. from its mouth. Its capital is called Banjul. It is an enclave of the Republic of Senegal and it has an area of about $10,360 \mathrm{sq} . \mathrm{km}$. and a population of about 500,000 (population census 1973). The population density, 50 per sq. $\mathrm{km}$. is one of the highest in Africa. The Country is easily accessible.

Leprosy Control in the Gambia is done by a specialized service of the Medical and Health Department, which started its activities in 1957.

General Medical Services are developing fast but are still insufficient in their coverage.

\section{Leprosy statistics}

\section{ESTIMATED PREVALENCE:}

In 1947, Ross ${ }^{1}$ (and others) surveyed 17,000 people and found the prevalence of leprosy to be $2.5 \%$. MacFadzean and McCourt ${ }^{2}$ found in 1954 a prevalence of $2.4 \%$. Based upon a random sample survey in 1977 and 1978 of 19,083 people, the prevalence is now estimated to be about $0.6 \%$. 
STATISTICS CONCERNING THE REGISTERED PATIENTS:

\section{(1) Total number}

At $31 / 12 / 78$ there were 1,594 patients registered or about $0.32 \%$ of the population. So about $50 \%$ of the estimated cases are under treatment.

$$
\begin{array}{rr}
\text { cf } 1957 & 800 \\
1960: & 6,207 \\
1970: & 7,000 \\
1975: & 2,483 \\
1976: & 1,784 \\
1977: & 1,675
\end{array}
$$

\section{(2) Sex distribution, age and classification in 1978}

In $1978,56 \%$ of the registered patients were male. Before 1976, always less than $50 \%$. 136 patients or $8 \%$ of the registered patients were 14 years or younger. In the beginning of the project this figure was much higher: $39 \%$ in 1961.

Classification is done according to Ridley and Jopling.

$$
\begin{aligned}
& \mathrm{TT}+\mathrm{T} \quad 728 \text { or } 45.7 \% \\
& \text { BT + BB } 435 \text { or } 27.3 \% \\
& \text { BL-L-LL } 420 \text { or } 26.3 \% \\
& \text { I } 5 \text { or } 0.3 \% \\
& \text { ? } 6 \text { or } 0.4 \%
\end{aligned}
$$

(3) Newly registered patients in 1978

Total number: 364

cf 1975: 228

cf 1976: 276

cf 1977: 210

Classification

TT-T: $\quad 260$ or $71.4 \%$ of the total newly registered patients.

TB-BB: $\quad 54$ or $14.8 \%$

BL-L-LL: 43 or $11.8 \%$

$$
\begin{aligned}
& \text { I: } 6 \text { or } 1.7 \% \\
& \text { ?: } 1 \text { or } 0.3 \%
\end{aligned}
$$

\section{Children}

63 or $17.4 \%$ of the newly registered patients were 14 years old or younger. None were lepromatous.

$$
\text { cf 1963: } 38 \%
$$




\section{Non-Gambians}

80 or $21.9 \%$ of the newly registered patients came from abroad. 15 or $19 \%$ of these were lepromatous.

\section{Disability}

46 or $12.6 \%$ of the newly registered patients were disabled.

Newly registered patients who had been treated before

At least 78 newly registered patients had been treated before with dapsone, in the Gambia or elsewhere.

Survey

159 or $44 \%$ of the newly registered patients were found during surveys.

(4) Discharged patients in 1978

Total number: 134 cf 1975: 616 cf 1976: 293 cf 1977: 187

(5) Out-of-control patients in 1978

$15 \%$ of the patients were defaulted in 1978

1976: $15 \%$

1977: $12 \%$

The lepromatous patients follow more or less the same pattern.

(6) Attendance rate $1976-1978$

The Medical Officer saw $60 \%$ of the patients which he should have seen.

(7) Dead patients in 1978

Total number: 32

cf 1975: 42

cf 1976: 25

cf 1977: 26

(8) Relapsed cases in 1978

6 patients discharged in the past relapsed.

(9) Disability in 1978

Disability is recorded in grades as recommended by the W.H.O. Figures of diability grade 1 are included. 
The total number of disabled patients receiving dapsone is at least 744 or $46 \%$ of the registered patients.

Number of patients with eye problems: 233

Number of patients with hand problems: 676

Number of patients with foot problems: 633

Disability not known: 86 patients or $5 \%$ of the registered patients. Ulcers: 246 patients have ulcers.

\section{Leprosy work}

\section{(1) Treatment}

Treatment is given by a field worker who visits the patient every 2 or 4 weeks on a motorcycle. Nearly all patients live within a mile from a treatment centre. All adult patients get $50 \mathrm{mgr}$. DDS daily.

New lepromatous patients (BL, L, LL) get $100 \mathrm{mgr}$. DDS daily; the first 4 months 100 mgr. clofazamine daily is added.

Leprosy patients are admitted in the general wards of the main hospital in the capital, for lepra reaction, ulcer care and eye-lid operations.

There is a small leprosy village up-country where 7 patients were admitted; mainly old, very disabled burntout cases.

An orthopaedic shoemaker is attached to the programme.

\section{(2) Case finding in 1978}

(a) School surveys

The total number of children seen in 1978 was at least 8,069 .

cf 1976: 8,114

cf 1977: 16,433

16 new cases were found, none disabled or lepromatous. Total prevalence of new cases found in school surveys $1976-1978$ is $0.104 \%$.

(b) Village surveys

In 1978 out of 49,501 people enumerated 33,071 were seen, or $67 \%$. cf in 1977: 21,530 seen. We found 143 new cases or $0.4 \%$ of the people seen.

Based on the 1977 and 1978 village surveys, of which a part was an at random sample $(21,450$ enumerated, 19,083 seen or $92 \%)$ the estimates as far as leprosy is concerned for the Gambia are as follows:

Prevalence rate of all leprosy cases is $0.6 \%$. (Standard deviation $0.036 \%$ ).

The prevalence rate in males is higher than in females. Of nonregistered cases $0.255 \%$ versus $0.248 \%$. 
The prevalence rate in the age group $0-14$ years is $0.2 \%$. For registered cases, $0.06 \%$; for non-registered, $0.14 \%$.

About $20 \%$ of the non-registered cases are non-Gambians.

About $5 \%$ of the non-registered cases will be disabled.

Most probably due to migration, the pattern of leprosy prevalence has changed. The Western Division always had the lowest prevalence and now has the highest. Nearly all BL-L-LL cases are under treatment.

(c) Prison surveys

All the prisoners in the country (522) were checked, 1 new T case was found.

(d) Public Works Department

300 staff members of the P.W.D. up-country were checked, 3 new T cases were found.

(e) Education

The Medical Officer gave lessons at the School of Public Health, the School of Nursing and the School of Community Nursing. During the school surveys talks about leprosy were given. A radio broadcast about leprosy was broadcast over Radio Gambia.

(f) Training paramedical staff

A refresher course was organized for all staff members.

(g) Staff and transport

Staff of the leprosy control project assisted in 1977 and 1978 with mass vaccination campaigns.

There are 11 leprosy field workers.

The field worker/patient ratio is low, 1:145. officer.

There are 4 Gambian senior staff and one expatriate medical

For transport the project makes use of 3 landrovers, 1 Peugeot and 15 motorcycles.

\section{Discussion}

Compared with the past, leprosy is nowadays a less serious problem:

(1) The estimated prevalence has come down from $2.5 \%$ in 1947 to $0.6 \%$ now.

(2) The number of patients under treatment has decreased from 7,000 in 1970 to less than 2,000 now.

(3) Only $8 \%$ of the registered patients are 14 years old or younger, compared with $39 \%$ in 1961 .

(4) Patients are now less disabled.

(5) We have the impression that nearly all BL-L-LL cases are now on treatment. 
But, after over 20 years of leprosy control only about a half of the patients needing chemotherapy receive it. The estimated prevalence $(0.6 \%)$ and the estimated prevalence rate for children $(0.2 \%)$ are such that, in the opinion of the author, leprosy control should still receive special attention. As long as basic general medical services are not within reasonable distance of the patient a specialised programme is needed. Migration over the border poses a special problem for leprosy control.

Both the total number of registered patients, 1,594, and the field-worker/ patient ratio $(1: 145)$ are low. To make more use of the project, other health activities should be undertaken. The staff has shown to be capable to do so.

\section{Acknowledgements}

I am greatly indebted to the Gambian Government which has given me the opportunity to work for three years as a Gambian Government servant. The Director Medical Services, Dr. Samba, was always helpful and very interested in the leprosy patients. As understood, the programme is a national programme and the Gambian Government pays all the local salaries, maintains the cars and buys drugs. Voluntary Agencies also make a substantial contribution, these are in alphabetical order: Canadian Leprosy Relief Association, Catholic Relief Services, I.D.A. (a Dutch non-profit-making pharmaceutical company), the Netherlands Leprosy Relief Association, Terre des Hommes (Netherlands), Weltfriedendienst (West Germany) and W.H.O.

\section{References}

1 Ross CM: Report on a sample medical survey of the Gambia in 1947. Government Printer, Bathurst, 1948.

2 McFadzean JA and McCourt JF: Leprosy in the Gambia. Lepr Rev, 1954, 26, 2, 57. 